\title{
Variasi Abu Ampas Tebu dan Serat Bambu sebagai Bahan Campuran Pembuatan Beton Ramah Lingkungan
}

\author{
Warsito ${ }^{1}$, Anita Rahmawati ${ }^{1}$ \\ ${ }^{1}$ Jurusan Teknik Sipil, Fakultas Teknik, UNISMA, Malang \\ Email: ar.nita.rachma@gmail.com
}

Received 13 Maret $2020 \mid$ Revised 20 Mei 2020 | Accepted 13 Juli 2020

\begin{abstract}
ABSTRAK
Beton merupakan suatu material yang secara umum menjadi kebutuhan masyarakat terhadap fasilitas infrastruktur konstruksi yang semakin meningkat seiring dengan perkembangan zaman, oleh sebab itu pemilihan beton sebagai bahan baku utama konstruksi bangunan sangatlah penting. Beberapa hal yang perlu ditinjau dalam pembuatan beton adalah harganya relatif murah, mudah diperoleh, memiliki kuat tekan tinggi serta mempunyai sifat tahan terhadap faktor kondisi lingkungan. Abu Ampas Tebu (AAT) adalah sisa hasil pembakaran dari ampas tebu. Ampas tebu sendiri merupakan hasil limbah buangan yang berlimpah dari proses pembuatan gula. Tujuan penelitian ini dimaksudkan untuk mengetahui kuat tekan beton yang menggunakan serat bambu dan abu ampas tebu sebagai pengganti agregat halus dengan variasi tertentu yang mencapai $40 \%$. Penelitian ini menggunakan metode kuantitatif eksperimen dan teknik analisa data menggunakan regresi. Variabel yang digunakan dalam penelitian ini adalah variabel bebas yang berupa variasi penggantian sebagian agregat halus menggunakan abu ampas tebu dan serat bambu. Hasil penelitian ini adalah beton dengan perbandingan komposisi campuran yang didapat sebelumnya dan hasil mix design beton normal maut sedang yaitu dengan besar kuat tekan $f_{c}$ ' 14,5 Mpa (K175) sampai dengan fc'17,15 Mpa $(K 210,6)$ yang kemudian ditambah dengan bahan AAT sebagai bahan penambah semen dan serat Bambu.
\end{abstract}

Kata Kunci: Abu Ampas Tebu, Beton, Serat Bambu, Agregat

\begin{abstract}
Concrete is a material that generally supports the community's need for construction of infrastructure facilities which is increasing along with the times. Selection of concrete as the main raw material for building construction is very important. There are benefits in making concrete such as low cost, ease to obtain, high compressive strength and resistancy to environmental conditions. Bagasse Ash (AAT) is the residue from the burning of sugarcane bagasse. Sugarcane bagasse itself is an abundant waste product from the sugar making processes. The purpose of this study was to determine the compressive strength of concrete using bamboo fibers and the AAT as a substitute for fine aggregate with certain variations reaching up to $40 \%$ with a concrete enhancer chemical aggregate. This research used the American Concrete Institute design method with a value of 0.40 and 0.45 on the concrete age of 28 days. Results found that the samples made were hard concrete with a comparison of the composition of the mixture obtained previously. Results of a normal deadly concrete mix design comprised with a large compressive strength $\mathrm{fc}_{\mathrm{C}}$ '14.5 Mpa (K175) to $\mathrm{fc}_{\mathrm{C}}{ }^{\prime} 17,15 \mathrm{Mpa}(\mathrm{K} 210,6)$ which was then added to the AAT as aggregates in the cement and Bamboo fiber.
\end{abstract}

Keywords: Bagasse Ash, Concrete, Bamboo, Aggregate 


\section{PENDAHULUAN}

Beton merupakan suatu material yang secara umum menjadi kebutuhan masyarakat terhadap fasilitas infrastruktur konstruksi yang semakin meningkat seiring dengan perkembangan zaman, oleh sebab itu pemilihan beton sebagai bahan baku utama konstruksi bangunan sangatlah penting. Beberapa hal yang perlu ditinjau dalam pembuatan beton adalah harganya relatif murah, mudah diperoleh, memiliki kuat tekan tinggi serta mempunyai sifat tahan terhadap faktor kondisi lingkungan.

Beton merupakan bahan yang bersifat getas dengan kuat tarik yang rendah. Kuat tarik beton dapat ditingkatkan dengan bahan tambah berupa serat (fiber). Sifat mekanik yang dapat diperbaiki dengan serat adalah daktilitas, serapan energi, ketahanan kejut, kapasitas lentur dan geser, ketahanan leleh (fatique) dan sebagainya. Jenis serat yang dapat dipergunakan untuk memperbaiki sifat mekanis beton antara lain adalah serat baja (steel fibre), serat kaca (glass fiber), serat polypropylene (sejenis plastik mutu tinggi), karbon (carbon) serta serat alami yang berasal dari bahan alami (natural fibre), seperti ijuk, sabut kelapa, serat goni, serat bambu, dan lainnya.

Abu Ampas Tebu (AAT) adalah sisa hasil pembakaran dari ampas tebu. Ampas tebu sendiri merupakanhasil limbah buangan yang berlimpah dari proses pembuatan gula. Pembakaran ampas tebu memiliki unsur yang bermanfaat untuk peningkatan kekuatan beton, karena menurut [1] abu ampas tebu mempunyai sifat pozzolan dan mengandung silica yang menonjol. Bila unsur ini dicampur dengan semen akan menghasilkan kekuatan yang lebih tinggi. Dari penelitian sebelumnya [2] didapatkan bahwa hasil pengujian oleh balai Riset dan Standarisasi Industri Manado diperoleh kandungan silika abu ampas tebu sebesar $68,5 \%$ sehingga memiliki sifat pozzolan. Penambahan serat alami (natural fiber), khususnya serat bambu menjadi pilihan karena merupakan produk hasil alam yang mudah dibudidayakan. Bambu memiliki beberapa kelebihan yaitu: tidak mengalami korosi, relatif murah, dan sifat kembang susut yang rendah, dan kuat tarik yang relatif tinggi. Menurut [3] bambu mempunyai kekuatan tarik dua kali lebih besar dibandingkan dengan kayu, apabila dibandingkan dengan baja yang mempunyai berat jenis antara $6,0-8,0$ (sementara $\mathrm{BJ}$ bambu $=0,6-0,8)$, kuat tarik baja hanya sebesar 2,3 - 3 lebih besar dibandingkan dengan kekuatan tarik bambu. Dengan demikian bambu mempunyai kekuatan tarik per unit berat jenisnya sebesar 3-4 kali lebih besar dibandingkan dengan baja [4]. Penelitian ini menitik beratkan pada penentuan optimasi pengaruh penambahan serat bambu terhadap sifat mekanik beton normal

Berdasar hal tersebut, maka penelitian ini dimaksudkan untuk mengetahui kuat tekan beton yang menggunakan serat bambu dan Abu Ampas tebu sebagai pengganti agregat halus dengan variasi tertentu yang mencapai $40 \%$ ditambah dengan Bestmittel sebagai bahan tambah kimia (chemical admixture) [5]. Pada penelitian ini akan digunakan metode perancangan ACI (American Concrete Institute) dengan nilai fas 0,40 dan 0,45 pada umur beton 28 hari.

\section{METODOLOGI}

Metode yang digunakan dalam penelitian ini adalah metode kuantitatif dengan desain penelitian eksperimental yang dilakukan di laboratorium untuk memberikan suatu gambaran mengenai pengaruh penggunaan abu ampas tebu dan serat bambu tehadap kuat lekat. Persentase penambahan abu ampas tebu tehadap volume agregat halus yaitu $0 \%, 10 \%$, dan $30 \%$. Sedangkan persentase penambahan serat bambu terhadap berat semen yaitu $0 \%, 1,5 \%$, dan $3 \%$. Sampel yang digunakan 
berupa beton berbentuk silinder dengan diameter $15 \mathrm{~cm}$ dan tinggi $30 \mathrm{~cm}$ sebanyak 36 buah yang dapat dilihat pada tabel berikut:

Tabel 1. Sampel benda uji

\begin{tabular}{|c|c|c|c|c|}
\hline No & $\mathbf{A A T}$ & $\begin{array}{c}\text { Serat } \\
\text { Bambu }\end{array}$ & $\begin{array}{c}\text { Benda } \\
\text { Uji }\end{array}$ & Jumlah \\
\hline \multirow{5}{*}{1} & \multirow{5}{*}{$0 \%$} & $1,5 \%$ & & \\
\hline & & $2 \%$ & 4 & 12 \\
\hline & & $0 \%$ & & \\
\hline & & $1,5 \%$ & & \\
\hline & & $2 \%$ & & \\
\hline \multirow[t]{4}{*}{2} & \multirow[t]{4}{*}{$10 \%$} & & 4 & 12 \\
\hline & & $0 \%$ & & \\
\hline & & $1,5 \%$ & & \\
\hline & & $2 \%$ & & \\
\hline \multirow[t]{2}{*}{3} & $20 \%$ & & 4 & 12 \\
\hline & & $0 \%$ & & \\
\hline
\end{tabular}

Tabel 2. Hasil pengujian agregat halus

\begin{tabular}{llll}
\hline \multicolumn{3}{c}{ Hasil Pengujian Agregat Kasar } \\
\hline Parameter & Hasil & Standar & Keterangan \\
\hline Abrasi & $20 \%$ & $<50 \%$ & $\begin{array}{l}\text { Memenuhi } \\
\text { standar }\end{array}$ \\
\hline $\begin{array}{l}\text { Bulk Specific } \\
\text { Gravity SSD }\end{array}$ & 2,4 & $2,5-2,7$ & $\begin{array}{l}\text { Termasuk } \\
\text { agregat kasar } \\
\text { tidak } \\
\text { normal }\end{array}$ \\
& & & $\begin{array}{l}\text { Termasuk } \\
\text { agregat kasar } \\
\text { tidak } \\
\text { normal }\end{array}$ \\
\hline $\begin{array}{l}\text { Modulus } \\
\text { Kehalusan } \\
\text { Butir kerikil }\end{array}$ & 5,6 & $6-7,1$ & \\
& Termasuk & & \\
& Daerah II & & \\
\hline
\end{tabular}

Adapun alat-alat yang digunakan dalam penelitian ini adalah mesin penekan yang berfungsi untuk menguji kuat tekan; meja penggetar berfungsi membebaskan tuangan dari pas pencetakan dilakukan pemukulan; cetakan benda uji berfungsi untuk mencetak benda uji; tongkat pemadat berfungsi untuk mengetahui nilai slump; mistar baja berfungsi untuk meratakan adonan; timbangan berfungsi untuk mengukur massa suatu benda; dan Compression testing.

Kemudian, untuk bahan yang diperlukan dalam pembuatan beton di penelitian ini adalah semen; air; pasir; Abu Ampas Tebu; dan Serat Bambu dengan perbandingan seperti pada Tabel 1 dan Tabel 2 di atas. 
Langkah-langkah dalam penelitian ini bisa dilihat pada flowchart pada Gambar 2 berikut.

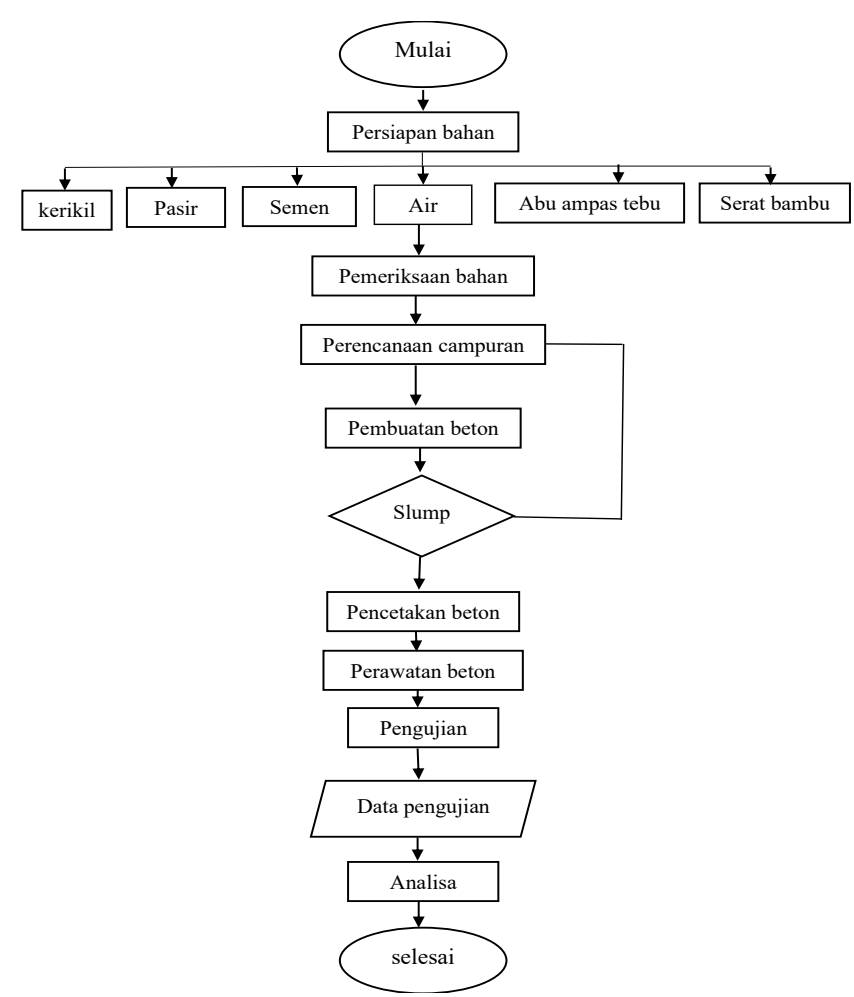

Gambar 2 Flowchart Penelitian

\section{HASIL DAN PEMBAHASAN}

\subsection{Hasil}

Penggunaan AAT $0 \%$ sampai $20 \%$ cenderung mengalami kenaikan kuat lekat beton serat tetapi pada variasi $5 \%$ sampai $15 \%$ pada beton mengalami penurunan kuat lekat. Penurunan terjadi dikarenakan penambahan persentasi AAT ditambah. AAT memiliki butiran yang sangat halus. Hal tersebut menyebabkan terjadinya lemahnya ikatan tulangan baja polos dan beton, hal tersebut juga menyebabkan beton memiliki rongga pada area tulangan benda uji. Oleh karena itu ikatan antar tulangan baja polos dan campuran beton serat melemah.

\subsection{Mix Desain}

Desain pencampuran bahan dalam studi ini diberikan pada Tabel 3 di bawah ini yang memberikan hubungan antara mutu beton, berat semen, pasir, kerikil, air dan rasionya. 
Tabel 3 : Desain pencampuran bahan

\begin{tabular}{cccccc}
\hline Mutu Beton & Semen (kg) & Pasir (kg) & Kerikil (kg) & Air (liter) & w/c ratio \\
\hline 7,4 Mpa (K100) & 247 & 869 & 999 & 215 & 0,87 \\
\hline 9,8 Mpa (K125) & 276 & 828 & 1012 & 215 & 0,78 \\
\hline 12,2 Mpa (K150) & 299 & 799 & 1017 & 215 & 0,72 \\
\hline 14,5 Mpa (K175) & 326 & 760 & 1029 & 215 & 0,66 \\
\hline $16,9 \mathrm{Mpa} \mathrm{(K200)}$ & 352 & 731 & 1031 & 215 & 0,61 \\
\hline $19,3 \mathrm{Mpa} \mathrm{(K225)}$ & 371 & 698 & 1047 & 215 & 0,58 \\
\hline $21,7 \mathrm{Mpa} \mathrm{(K250)}$ & 384 & 692 & 1039 & 215 & 0,56 \\
\hline $24,0 \mathrm{Mpa} \mathrm{(K275)}$ & 406 & 684 & 1026 & 215 & 0,53 \\
\hline 26,4 Mpa (K300) & 413 & 681 & 1021 & 215 & 0,52 \\
\hline $28,8 \mathrm{Mpa} \mathrm{(K325)}$ & 439 & 670 & 1006 & 215 & 0,49 \\
\hline $31,2 \mathrm{Mpa} \mathrm{(K350)}$ & 448 & 667 & 1000 & 215 & 0,48 \\
\hline
\end{tabular}

Sumber : [6]

\subsubsection{Mix design (K 175)}

Contoh dalam pengerjaan penelitian beton untuk mix desaign (K 175) dengan bahan-bahan seperti: semen $=326 \mathrm{~kg}:$ pasir $=760 \mathrm{~kg}:$ kerikil $=1029 \mathrm{~kg}$, dengan konversi perbandingan $1: 2: 3$. Apabila perbandingan $326: 760: 1029$ maka rasio dapat dihitung dengan $(326 / 326):(760 / 326):(1029 / 326)=$ $1: 2.33: 3.15$. Maka dianggap air yang diberikan juga sesuai tabel tersebut, yaitu $0.66 \mathrm{~kg}$. Kebutuhan air kemudian dapat dihitung yaitu $(215 / 326)=0.66 \mathrm{~kg}$ dari kerapatan/berat jenis material tersebut.

Untuk mendapatkan nilai yang akurat dari material tersebut biasanya dilakukan pengujian di laboratorium. Akan tetapi apabila tidak ada data, dapat kita ambil nilai berikut dan sudah cukup mewakili. Jadi untuk membuat beton k-175, cukup dengan mengambil 1 ember semen dengan 2 ember pasir dan 3 ember kerikil, dengan catatan ember yang digunakan harus sama, dan memakai air sebanyak 0.8244 ember.

\subsubsection{Volume Benda Uji}

Benda uji tabung

Diketahui : $\mathrm{d}=15 \mathrm{~cm} ; \mathrm{t}=30 \mathrm{~cm}$

Penyelesaian: $\mathrm{V} \quad=3,14 \times 7.52 \times 30$

$$
=5298,75 \mathrm{~cm}^{3}=0,005298 \mathrm{~m}^{3}
$$

1 zak semen isi $50 \mathrm{~kg}$ mempunyai ukuran zak $10 \mathrm{~cm}$ x $40 \mathrm{~cm}$ x $60 \mathrm{~cm}$.

Jadi, semen isi $50 \mathrm{~kg}$ mempunyai volume : $0,024 \mathrm{~m} 3$

Sehingga, $1 \mathrm{~kg}$ semen $=(1 \mathrm{~kg} \times 0,00243) / 50 \mathrm{~kg}=0,000486 \mathrm{~m}^{3}$

Jumlah total keseluruhan dari tabel di atas adalah:

Perbandingan volume material $=2: 4: 6: 1$

- semen $=0,000972 \mathrm{~m}^{3}$

- pasir $=0,001944 \mathrm{~m}^{3}$

- koral $=0,002916 \mathrm{~m}^{3}$

- air $=0,000486 \mathrm{~m}^{3}$

$\mathrm{n} \quad=0,006318 \mathrm{~m}^{3}$ 
- Jadi, 1 benda uji tabung volume $0,005298 \mathrm{~m} 3$, maka 108 benda uji mebutuhkan ( 108 x 0,005298 $\mathrm{m} 3)=0,57 \mathrm{~m} 3$

- Semen $(\mathrm{S}) 0 \%-30 \%=(18 \times 3)+(16,2 \times 3)+(14,4 \times 3)+(12,6 \times 3)$

$=54+48,6+43,2+37,8$

$=183,6 \mathrm{~kg}$

- $\quad$ Abu ampas tebu $($ AAT $)=(1,8 \times 3)+(3,6 \times 3)+(5,4 \times 3)$

$=5,4+10,8+16,2$

$=32,4 \mathrm{~kg}$

- $\quad \operatorname{Pasir}(\mathrm{P})$

$=432 \mathrm{~kg}$

- $\quad$ Kerikil (K)

$=216+212,76+209,52$

$=638,28 \mathrm{~kg}$

- $\quad$ Serat bambu (SB) $0 \%-3 \%=(0,81 \times 4)+(1,62 \times 4)$

$=3,24+6,48$

$=9,72$

- $\quad$ Air W/C $(0,66) \quad=1,34$ liter

$=1,34 \times 108$ benda uji

$=144,72$ liter

\subsubsection{Hasil percobaan slumptest}

Hasil slumptest dari percobaan pembuatan beton mutu K175 dengan diiameter atas slump $=4 \mathrm{~cm}$; diameter bawah slump $=8 \mathrm{~cm}$; tinggi slump $=30 \mathrm{~cm}$; harga slump $=$ penurunan dari adukan semula; tinggi penurunan $=5 \mathrm{~cm}$. Sehingga, selanjutnya harga slump dapat dihitung dengan membuat selisih antara tinggi slump dengan tinggi penurunan, sehngga didapat nilai sebesar $25 \mathrm{~cm}$.

\subsection{Uji kuat tekan beton}

Cara yang digunakan untuk pengujian kuat tekan beton adalah dengan menggunakan mesin tekan dan hasilnya dapat dilihat pada Tabel 4.

Tabel 4 Nilai standar deviasi (himsworth)

\begin{tabular}{cccccc}
\hline Jenis Pengawasan & sempurna & $\begin{array}{c}\text { Sangat } \\
\text { baik }\end{array}$ & Baik & Cukup & Buruk \\
\hline Standar Deviasi Mpa & 2,8 & 3,5 & 4,2 & 5,6 & 7 \\
\hline
\end{tabular}

Sumber : [6]

Prinsip pengujian kuat tekan beton dengan alat mesin tekan adalah mengukur besarnya beban yang dapat dipukuli oleh satuan luas beton (benda uji) samapai bend uji itu hancur atau rusak. Adapun bentuk benda uji dapat berupa kubus ukuran $15 \mathrm{~cm}$ atau silinder $\varnothing 15 \mathrm{~cm}$ dan tinggi $30 \mathrm{~cm}$.

Kekuatan beton atau mutu beton seringkali kita jumpai dengan notasi " $\mathrm{f}$ " c" atau " $\mathrm{K}$ " mutu beton $\mathrm{f}$ " dinyatakan dalam satuan Mpa. Beton dengan mutu f'c 14,5 Mpa menyatakan kuat tekan beton tersebut adalah 14,5 Mpa pada umur 28 hari dengan menggunakan benda uji silinder ukuran diameter $15 \mathrm{~cm} \mathrm{x}$ tinggi $30 \mathrm{~cm}$. $1 \mathrm{Mpa}=1 \mathrm{~N} / \mathrm{mm} 2=10,2 \mathrm{~kg} / \mathrm{cm} 2$. Sedangkan mutu beton $\mathrm{K}$ dinyatakan dalam satuan $\mathrm{kg} / \mathrm{cm}^{2}$. Beton dengan mutu K 175 menyatakan kuat tekan beton tersebut adalah $175 \mathrm{~kg} / \mathrm{cm}^{2}$ pada umur 28 hari dengan menggunakan benda uji silinder. Rumus yang digunakan untuk menghitung parameter kuat tekan (f'c dalam Mpa atau $\mathrm{kg} / \mathrm{cm}^{2}$ ) mengacu pada [7]. 
Setelah diperoleh nilai f'c maka nilai tersebut dibagi faktor umur beton yaitu:

- $\quad 0,46$ untuk umur 3 hari

- $\quad 0,65$ untuk umur 7 hari

- $\quad 0,88$ untuk umur 14 hari

- $\quad 0,96$ untuk umur 21 hari

- $\quad 1,00$ untuk umur 28 hari.

Setelah hasil bagi kuat tekan dibagi dengan faktor umur, maka nilai tersebut di bagi lagi dengan faktor bentuk sampel:

- $\quad 1$ untuk benda uji kubus ukuran $15 \times 15$ x $15 \mathrm{~cm}$

- $\quad 0,83$ untuk benda uji silinder ukuran diameter $15 \mathrm{~cm} \times$ tinggi $30 \mathrm{~cm}$

\subsubsection{Perhitungan}

Untuk umur beton 14 hari, maka $\sigma b$, dapat dihitung dengan persamaan berikut:

$$
\begin{aligned}
& \sigma \mathrm{b}=\frac{\text { Tegangan tekan }}{k \times \text { Luas penampang }} \\
& \sigma \mathrm{b} \quad=\frac{36709,2}{0,88 \times 176,625} \\
& \sigma \mathrm{b}=236,18 \mathrm{~kg} / \mathrm{cm}^{2} \\
& \sigma \mathrm{bm}=\frac{\Sigma \sigma \mathrm{b}}{n} \\
& \sigma \mathrm{bm}=\frac{557,64}{3} \\
& \sigma \mathrm{bm}=185,88 \mathrm{~kg} / \mathrm{cm}^{2} \\
& \sigma \mathrm{bm}_{\mathrm{akhir}} \quad=\frac{\sigma b m}{0,83} \\
& \sigma \mathrm{bm}_{\mathrm{akhir}} \quad=\frac{185,88}{0,83} \\
& \sigma \mathrm{bm}_{\text {akhir }} \quad=223,95 \mathrm{~kg} / \mathrm{cm}^{2}
\end{aligned}
$$

Umur beton 21 hari

$$
\begin{array}{ll}
\sigma \mathrm{b} & =\frac{\text { Tegangan tekan }}{k \times \text { Luas penampang }} \\
\sigma \mathrm{b} & =\frac{28551,6}{0,96 \times 176,625} \\
\sigma \mathrm{b} & =168,39 \mathrm{~kg} / \mathrm{cm}^{2} \\
\sigma \mathrm{bm}=\frac{\Sigma \sigma \mathrm{b}}{n} & \\
\sigma \mathrm{bm}=\frac{523,20}{3} & \\
\sigma \mathrm{bm}=174,40 \mathrm{~kg} / \mathrm{cm}^{2}
\end{array}
$$




$$
\begin{aligned}
\sigma \mathrm{bm}_{\text {akhir }} & =\frac{\sigma b m}{0,83} \\
\sigma \mathrm{bm}_{\text {akhir }} & =\frac{174,40}{0,83} \\
\sigma_{\text {bm }} \text { akhir } & =210,12 \mathrm{~kg} / \mathrm{cm}^{2}
\end{aligned}
$$

- Umur beton 28 hari

$$
\begin{aligned}
& \sigma \mathrm{b}=\frac{\text { Tegangan tekan }}{k \times \text { Luas penampang }} \\
& \text { } \sigma \mathrm{b}=\frac{31610,7}{1 \times 176,625} \\
& \sigma \mathrm{b}=178,97 \mathrm{~kg} / \mathrm{cm}^{2} \\
& \sigma \mathrm{bm}=\frac{\Sigma \sigma \mathrm{b}}{n} \\
& \sigma \mathrm{bm}=\frac{519,59}{3} \\
& \sigma \mathrm{bm}=173,20 \mathrm{~kg} / \mathrm{cm}^{2} \\
& \sigma \mathrm{bm}_{\mathrm{akhir}} \quad=\frac{\sigma b m}{0,83} \\
& \sigma \mathrm{bm}_{\mathrm{akhir}} \quad=\frac{173,20}{0,83} \\
& \sigma b_{\text {akhir }}=208,67 \mathrm{~kg} / \mathrm{cm}^{2}
\end{aligned}
$$

Maka nilai $\sigma b$ bervariasi dengan parameter umur beton. Semakin muda umur beton maka nilainya akan semakin tinggi.

\section{SIMPULAN}

Dari hasil penelitian yang sudah dilakukan di laboratorium Universitas Islam Malang, sampel yang dibuat adalah beton keras dengan perbandingan komposisi campuran yang didapat sebelumnya dan hasil mix design beton normal maut sedang yaitu dengan besar kuat tekan fc' 14,5 Mpa (K175) sampai dengan fc'17,15 Mpa (K210,6) yang kemudian ditambah dengan bahan Abu Ampas Tebu (AAT) sebagai bahan penambah semen dan serat Bambu (SB).

Penambahan bahan AAT dan SB yang memenuhi syarat yang direncanakan untuk mutu beton fc' 14,5 Mpa (K 175) adalah :

- AAT $0 \%$ - SB 1,5\% dengan mutu beton $14,87 \mathrm{Mpa}(\mathrm{K} 182,87)$

- AAT 10\% - SB 0\% dengan mutu beton fc' 15,82 Mpa (K 194,28)

- AAT 10\% - SB 3\% dengan mutu beton fc' 14,59Mpa (K 179,2). 
Penambahan bahan AAT dan SB yang tidak memenuhi syarat yang direncanakan untuk mutu beton fc' 14,5 Mpa (K 175) adalah :

- AAT 0\% - SB 3\% denga mutu beton fc' $12,52 \mathrm{Mpa}(\mathrm{K} 153,8)$

- AAT 10\% - SB 1,5\% dengan mutu beton fc' 13,54 Mpa (K 166,25)

- AAT $20 \%$ - SB 0\% dengan mutu beton fc' $10,42 \mathrm{Mpa}(\mathrm{K} 127,94)$

- AAT $20 \%$ - SB $1,5 \%$ dengan mutu beton fc' $7,48 \mathrm{Mpa}(\mathrm{K} 91,92)$

- AAT 20\% - SB 3\% dengan mutu beton fc' 8,21 Mpa (K 100,88)

- AAT 30\% - SB 0\% dengan mutu beton fc' 6,68 Mpa (K 82,07)

- AAT 30\% - SB 1,5\% dengan mutu beton fc' $6,52 \mathrm{Mpa}(\mathrm{K} 80,06)$

- AAT 30\% - SB 3\% dengan mutu beton fc' 7,08 Mpa (K 86,99).

\section{DAFTAR PUSTAKA}

[1] Alfredo, M. (2012). Studi Tekan Beton Normal Mutu Sedang dengan Campuran Abu Sekam Padi (RHA) dan Limbah Adukan Beton (CSW). Depok: Universitas Indonesia.

[2] Rompas, G.P., dkk. (2013). Pengaruh Pemanfaatan Abu Ampas Tebu Sebagai Subsitusi Parsial Semen Dalam Campuran Beton Ditinjau Terhadap Kuat Tarik Lentur dan Modulus Elastisitas, jurnal sipil static Vol.1 No.2 82-89.

[3] Morisco. (1996). Bambu Sebagai Bahan Rekayasa, Pidato Pengukuhan Jabatan Lektor Kepala Madya, Yogyakarta: Universitas Gajah Mada, Fakultas Teknik.

[4] Morisco. (1999). Rekayasa Bambu, Nafiri Offset, Yogyakarta.

[5] Isnawati. (2015). Pengaruh Penambahan Agregat Limbah Plastik Terhadap Kuat Tekan Beton. Makassar: Universitas Islam Negeri Alauddin.

[6] SNI DT-91-0008-2007. (2007). Tata cara perhitungan harga stauan pekerjaan beton untuk konstruksi bangungan gedung dan perumahan. Badan Standardisasi Nasional (BSN).

[7] SNI 03-1974-1990. (1990). Pengujian Kuat Tekan Beton, Badan Standardisasi Nasional. 